\title{
Service Evaluation and Customer Orientation using Need Based Approach to Enhance Effectiveness in Public Sector Marketing
}

\author{
Ahmad Nawaz Zaheer ${ }^{1}$ \\ Dr. Song Wei2 \\ Ghulam Nabi3 \\ Mohamed Noureldin Attia ${ }^{4}$ \\ Kashif Ullah Khan ${ }^{5}$ \\ Fakhra Rashid 6 \\ ${ }^{1}$ School of Public Affairs, University of Science and Technology of China, Hefei 230026, Anhui, China \\ Corresponding Email : songwei@ustc.edu.cn; anzaheer@mail.ustc.edu.cn \\ 2University of Science and Technology of China, (School of Public Affairs, University of Science and \\ Technology of China, Hefei 230026, Anhui, China)
}

\section{Doi:10.5901/mjss.2016.v7n3s1p155}

\begin{abstract}
Marketing approach rarely moves ahead without self-interest. This inculcates a strong link between customer orientation and strategies followed for public sector marking. In case of China, due to huge population, there seems a greater challenge to maintain quality services and public satisfaction. Taking into account the extensively developed railway network, we conducted a survey of customers utilizing train services in China with an aim to document train service effectiveness in relation to satisfaction and perceived customer orientation. The evaluation was based on questionnaire specifically prepared to analyze public sector marketing effects on shaping views of train customers who travel within China through railway network. Results enabled us to construct a model that clearly indicates speed, comfort, cleanliness and flexible train schedules have strong positive impact train users. Marketing focus on purchase of tickets such as online buying and information about train schedules inside stations has inspired huge population to prefer travelling through train than any other means. Our findings show that well planned customer orientation before public service marketing will create a customers need which can be set as political objective to enhance customer satisfaction by taking control of that need as in the case of China high speed train.
\end{abstract}

Keywords: customer orientation; high speed train; online services; customer feedback; public sector marketing

\section{Introduction}

The primary basic normal for the government organization's products are that it is prevalently a service item; it comprised on a tri-segment type of requirements, obligations and amenities and it shows features of pecuniary experts' idea of a "public good ". In the primary, government organization gives benefits instead of merchandise. The marketing ramifications of the service trademark incorporate the need to make substantial those parts of public service which resident shoppers discover hard to appreciate. Public sector organization in various countries logically sees the prerequisite for relentless quality change of the organizations gave and an interminably quick response to the growing needs and demands citizens or client. Broadly talking, there is right now a need to direct citizen's faithfulness even with a trouble; the essential to give organizations at the biggest sum whilst meanwhile going up against the need to cut government utilization

Numerous public sector supervisors realize that marketing is more than interchanges or sales, yet they don't have the foggiest idea about the "enchantment" that makes it work. When they comprehend the four Ps-product, price, place, and promotion they can utilize them to change their correspondence with public and enhance their execution (Philip Kotler \& Lee, 2007). With the movement of the public sector to a greater extent an administrative, professional loom, the appropriation of marketing activities can provide as an important part in reinforcing responsibility and changing 
government business into manageable operation(Church, n.d.). This line of attack has essential for public sector directors to learn and rehearse a scope of new marketing aptitudes (Sargeant, 1999)

Kotler and Lee (2007) clarified that key marketing planning is a fundamental administration device. It relies on upon a citizen focused approach and utilizes a custom mix of the advertiser's techniques, which the private and not-forprofit segments have been utilizing for a considerable length of time. It is a train that can be sent to change any public organization into a practical organization. What does "marketing" infer? Advertising or selling. Actually, these are strategies of the final resort, utilized when marketing standards and methods have not been appropriately utilized to create value, disseminate and viably impart the genuine estimation of an association's offerings. They demonstrate an absence of a customer-oriented mindset.

Public sector marketing can be utilized to accomplish the revelation of better viewing so as to advise and drawing in citizen's correspondences inside of a more extensive key marketing framework. It can reposition and make unrivaled picture for the organization, drive better results in project uptake, system effect and behavioral change. It can likewise draw in financial specialist's capital or spare cash by helping administrators and program or administration directors make educated speculation and resource trade-off decisions (James, Mintz and Doug, 2011).

Adding to "Marketing in Government", (Madill, 1998) repeated Proctor's (2007) attestation that, the public sector associations are worried with giving services instead of products. Advertising of services requires diverse methodology. Marketing a service based business contrasts from promoting a product based business.

Cowell (1984) contended that what is huge about services is the relative predominance of impalpable traits in the makeup of the 'service product'. As an outcome, administrations may require uncommon understanding and unique advertising endeavors. For instance, the personnel giving the service are pretty much as essential as the service itself and the association between service supplier and service beneficiary is of central significance. Service based associations are basically worried with overseeing relations on the grounds that they deal with the aggregate "buyerseller" communication process. This is done as a major aspect of pulling in, keeping up, and enhancing client connections (Reid, 2008)

Kotler and Lee (2007) included that, while numerous services marketed in public sector are manageable to the same sorts of treatment as one would take after with services in the private sector a few services have an alternate point. Utilization of marketing techniques and ideas inside of a few parts of public service are worried with advancing thoughts and are as often as possible alluded to as social marketing. Kotler \& Zaltman (1971)recommended that, social marketing is: "The design, implementation and control of programs calculated to influence the acceptability of social ideas and involving considerations of product, planning, pricing, communication, distribution and marketing research." Social advertising plans to realize particular behavioral objectives important to social great, for instance the anticipation of hostile to social conduct, for example, vandalism or liquor misuse in the community. On the other hand, it is one and only of various conceivable mediation strategies and its constraints or suitability for specific purposes has to be surely known.

On the subject of Marketing difficulties confronted by public sector administrators the CEPSM (2006) directed a study to survey the soundness of promoting out in the government sector in Canada (Mintz, Partner, \& Sector, 2006). The survey likewise called attention to that Government as a rule, exhibited disregard for consolidating a recognized marketing procedure and setting up quantifiable marketing goals and scored low on executing a proactive procedure that inculcate customer desires when recognizing and growing new offerings( product, services and program)

Cousins (1990) clarified that, in the 1990s, various European's public sector began to see its general public as clients and observed the huge benefit of their marketing practice in their day to day activities and planning for marketing efforts keeping in mind the end goal to "sell" strategies to nationals. Public sectors utilize four sorts of marketing, which vary from one another in the targets fundamental them.

1- "Marketisation" implies that, definite parts of public sector movements get to be similar to business subjecting so as to promote in the private sector offerings to the aggressive strengths of market. The main concentration was to reduce the cost and offered the more valued products and services as per customer demands (Chapman \& Cowdell, 1998)

2- Every organization wants to promote their self interest and marketing plays very important role in this. For instance, (Burton, 1999) proposed that most of the organization in public sector utilized partner advertising to make safe their proceeded with presence by backing from the business sector and the social order.

3- Thirdly, the local authorities and powers, advertising are utilized to advance the region beneath the obligation of the public sector for example, "city marketing'.

4- At long last, marketing might be influential in advancing main political destinations, for instance the acknowledgment of social impacts. Advertising abilities created in the private segment can be utilized in the public sector to advance and convey non-benefit inspired administrations. A municipal council, for instance, 
can have a 'product mix' which includes product classes from a plant nursery to decline accumulation and a legitimate division, and can utilize the same methods as private sector marketers.

Before, public sector organizations have focused more in transit in which services are conveyed as opposed to accentuation on customer or end user. Apparently that have created in light of the fact that an organization has had a thought of what the client needed, or considered that it realized what the client required from an expert point of view (Bean \& Hussey, 2012). Marketing standards can be connected inside of public sector however there may be trouble in relating service conveyance totally to market standards. In proposing that "market" standards may be connected in public sector, there is a presumption that the business sector is a productive and proper assigning component for appropriating open segment merchandise and administrations. Mellors (1993) contended that the thought of a 'public good' and 'public interest' stay hazardous in receiving business sector answers for service provision. In any case, whatever the connection, marketing standards can apply and staff should be marketing focused.

As Public sector organization everywhere throughout the Western world has moved toward managerialism toward the 80s' start, 'marketing has additionally expanded in significance. Alongside the new public administration development an adjustment in the relationship between the organization and the subjects has gotten to be clear, open division in different European nations began seeing nationals as clients, further start applying marketing in their day to day activities and starts planning for this (Cousins, 1990) with an objective to satisfy the customer and fulfill the need of the customer in a better way.

The primary two purposes behind which the utilization of marketing in public sector is unavoidable as mentioned by Proctor (2007). The first reason is "Scarcity of resources" especially fiscal ones. This issue has been an unfaltering issue starting from the ' $80 \mathrm{~s}$ as a result of, from one perspective, reliable augmentation of enthusiasm for better and more different public service and, on the other hand, by higher disillusionment with the execution of the association and in this way a diminished preparation to contribute fiscally and socially. The second reason is expanded rivalry from the private organization. Last couple of decade, a standout amongst the most widely recognized parts of any change development in public sector has been the presentation of rivalry in the public segment.

Public sector in the country has long had segments of advertising yet they have as a general rule been fringe to the acquirement of focus public merchandise and administrations (Serrat, 2010) - take for instance exercises done in advancing tourism or certain products of state owned companies. The initial step is to acknowledge marketing as something key for any public sector. Besides, incorporating marketing as a component of the entire association methodology is something that is in the line of new changes where citizens' input is seen as more imperative for advancement and conveyance of services Another favorable position is that it accomplishes indicated incomes or costrecuperation targets (Serrat, 2010, p.4) .

The idea of marketing, in spite of the fact that with a background marked by just about a century, has continually developed, principally amid the most recent decades, turning out to be more unpredictable and broad. Maybe, one of the conceivable clarifications of this prevalence is that living in a general public in real part in light of the free market economy includes, in addition to other things, buying and selling various items and administrations went for raising the personal satisfaction. Buying and selling are additionally taking into account the idea of deliberate trade which further suggests pricing, promoting, branding or, in only single word, marketing.

While the idea of administration quality has, by and large, pulled in awesome consideration in the private part for quite a while, it has just entered the verbal confrontation in public sector organization literature all the more as of late. Further Parker\& Bradley (2000) and Kodylis (2011) discussed that public sector associations have been affected and characterized by political powers and focal bureaucratic organizations. In this bureaucratic model public segment representatives took after troublesome systems by standard to exhibit responsibility to general society (Claver, Llopis, Gascó, Molina, \& Conca, 1999; Bolton, 2003). The procurement of administrations was in this way more inside centered than being engaged towards the requirements of the national. All things considered, the idea of administration quality from the beneficiaries' point of view was unessential. With the presentation of the New Public Management approach it was would have liked to add to another administration introduction amongst public division associations. Further Giankis (2002) explained the market-driven concepts and said that organizational change outline is "oriented towards the development of post-bureaucratic organizational forms". Further the delivery of powerful and effective administrations and their change. In any case, various scholars contend that numerous public sector battle with this re-introduction because of the complexities of nature they are working in. For example, Marini (1993) highlights that public sector organizations are often used to demonstrate for instance of service carnage. Important to note in this entire debate is the dominating managerial focus, centering on questions concerning management, change to organizational structures and processes, and the difficulties that the employees face in this transition. Less attention is paid to the impact on potential service recital absorption between sectors has on recipients. 


\section{Customer Orientation in Public Sector}

Public sector marketing has developed from business promoting practices - the investigation by Kotler and Zaltman denoted its rise as an unmistakable control. Business marketing practices thus has developed through a progression of stages to its present day customer orientation. To start with the production orientation, the overwhelming business state of mind for the first half of this century is described by sympathy toward expanding yield and decreasing expense. The second period of business logic, a "sales orientation" has been encapsulated by an offering and advancement exertion coordinated toward producing high sales and high benefit. Social advertising system that depend upon advancement to "offer" items „, for example, exercise gear and "quit smoking" projects, are cases of this way to deal with wellbeing instruction. As opposed to the production and sales introductions, present day business marketing locations the customer's requirements and hobbies in the improvement and advancement of products and services.

As indicated by Narver \& Slater (1990), customer orientation is a piece of business sector introduction yet a few creators characterized it all the more definitely. Furthermore the concept of customer orientation is explained by Shapiro (1988) which is "the dissemination of information about customers throughout an organization, formulation of strategies and tactics to satisfy market needs inter-functionally and achievement of a sense of company-wide commitment to these plans" .Customer orientation arrives displayed as an authoritative society that is dedicated to fulfill clients' necessities on their business sector. As per Shapiro 1988) that behavior is produced through correspondence or "dissemination of information" all through the organization. Kohli \& Jaworski (1990) likewise propose that client introduction "represents the degree to which customer information is both collected and used by the business unit".

At last, for Deshpandé, Farley, \& Webster Jr (1993) discussed the customer orientation and described that "the set of beliefs that puts the customer's interest first, while not excluding those of all other stakeholders such as owners, managers, employees, in order to develop a long-term profitable enterprise". Therefore, Customer orientation use to be significant part of an authoritative society and regard for information about clients' requirements ought to be considered as a fundamental estimation of the firm. Appiah-Adu \& Singh(1998) further contributed and said "customer orientation is a concept comprising customer understanding orientation and customer satisfaction focus". Further they explained that this is the motivation behind why client introduction includes social mentalities, for example, creating and improving quality to clients. Customer orientation is about execution and since society is "how things are done" customer orientation ought to pervade the general exercises of an organization.

Mainstreaming the necessities of individual signifies "to deal with a product for all" idea is out of date. Clients now need more altered administration from suppliers, and are willing to pay the comparing cost. For suppliers, the primary precondition of procurement of tweaked item or administration is to have the capacity to plainly separate and distinguish the business sector. The business sector can be completely portioned, which implies a definitive objective is that every client will be a business sector fragment. In complete business sector fragments, suppliers will give redid administrations or products to every client. Regardless of the possibility that the business sector can be completely portioned to every client, the following most concerning issue is to tell whether this model is commendable from the business appraisal, that is, to pick a level of beneficial customization (Fang, Xiaoping, Chen, Zhiya and Li, Zhizhong, 2003). This is identified with the way of the business sectors confronted by the producer. Here, the measure of an individual business sector portion should be investigated. In particular, the size can be separated into four related viewpoints: single exchange volume, whether there are ceaseless exchange needs, normal yearly exchange measure of a solitary client and the aggregate number of clients. By and large, institutional customer has a greater exchange than individual client does. Institutional customer's obtained types of equipment and auxiliary specialized administrations and individual buyer's durables are discontinuous requests; while institutional customer's requirement for crude materials, fuel, parts and specialized support administrations, and individual purchaser's consumables are constant requests. China railroad cargo transport division mostly gives administration to institutional customer's products transport and logistics interest, which is an extroverted and stable concern. Therefore the institutional customers build the level of cost control, there will be an tendency of littler volumes and more clumps.

Customer orientation lies in the way that all moves ought to make into record the needs, prerequisites and desires of clients. In connection to the administrations gave by public organizations, it can hence be presumed that need will be met through conferment of administrations to the customer (e.g. issuing an identity card), necessities will be met given the administration rendered meets specific parameters (is done appropriately, as per the regulations, is not flawed, and so forth.), while desires are met when the administration is rendered to the beneficiary in the route in which the client wishes to be served, and not surprisingly (e.g. decent environment, comparing to the customer's likelihood getting administrations, and so forth.). Today, numerous ideas hold customer orientation as a central guideline. 


\section{Excellence of Services Provided by the Public Sector}

In last couple of years, public sector viability, execution and organization quality had been able to be best issue of government association. Therefore client situated administration attitude was the top undertaking of public segments or associations and all individuals should concentrate on clients. At the point when going to open segment for public undertakings, individuals frequently needed to visit different offices, rehashing rounding out the comparative structures; or going forward and backward offices with records in the segment framework with misty obligation division. With "customeroriented" administration mentality, client worth could be the critical premise of organization, specifically communicate with client (individuals), gather client related data, and along these lines enhance administration and item regulatory foundation gave (Chiang, 1999).

Font (1997) argued that government driven organization quality change must be assessed in perspective of customer, develop the degree a few units, offices, as well as learn achievement skill of private sector, and exchange to public sector function. Also, in related assessment, the part of individuals in quality assessment must be checked; inside assessment should consider dynamic support of association organization top supervisors and individuals. Individual's fulfillment related information might be surveyed by outer organization, looking at contrast of comparable gatherings or distinctive gatherings. Assessment result should be announced subsequent to a period to maintain time impact in order to be yardstick that government organizations can talk about change. It's recognized from over that, administration might modify service means and substance by method for reaching clients and knowing their interest, so clients get maximal fulfillment. Henceforth, future service quality might be without a doubt the way to enhancing organization execution and competency for public sector

\section{Public Services in China (Chinese Railways)}

In view of the fact that the reforms and opening to the outside world, the Chinese Economy has seen a fast extension. The information gathered by National Bureau of Statistic of China (2012a) affirmed that the GDP of China Surpassed Japan in 2010, and turned into the second biggest financial body on the planet. The public service is defined by legislation specifying the characteristic of the employees and the employing institutions, and the monopoly is the essential characteristic of public service of China (Xiong, 2009). According to the $12^{\text {th }}$ National Five year Plan of basic public service system of China published on July 11,2012, eight kinds of public services are included in the system, namely Public education, employment service, social security, basic social services, health services, family planning, house security and public culture. However, Railway passenger is not included in the system.

With the rapid development of Chinese economy, the public service system gets its initial effects, although it's barely in embryo stage, and nearly all the Chinese have been influenced in terms of living style and quality. Meanwhile innovations in the public service fields also cause some problems, especially in monopolized public sector service sectors, for example, China Railways.

The ministry of China Railways was established after the founding of People's Republic of China, which is responsible for the construction and management of railways all over China. There are six affiliated bureaus under the ministry's control, and each bureau is in charge of a specific area (The General Knowledge of Railways, 2013).

In 1949, China had only 102 million person travelling by railway and by 2011, the number reached 186 million, increased by $82 \%$. At the same time although the capacity of railways has been increased greatly, especially from 2005 to 2011, the gap between the demands and supply of passenger transportation was still as high as $43.09 \%$. Let alone during the Spring Festival Season

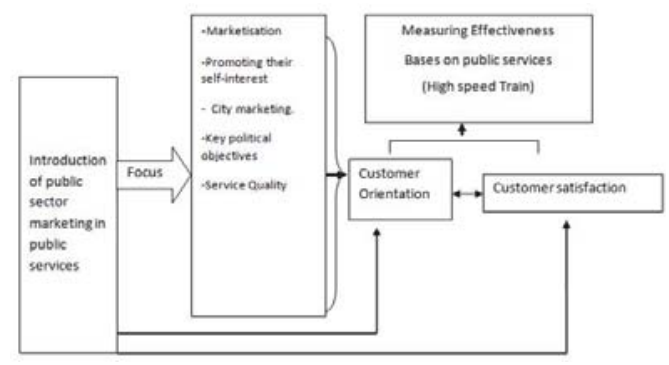


Figure 1: Conceptual framework

In order to conceptualize the context specificity of the implications of public sector marketing on customer orientation, a framework from the literature review is proposed in which the impact on customer satisfaction and customer orientation is described as a two stage process, the focus and outcome of which is determined by measuring effectiveness.

\section{Objective of the Study}

The goals of this study were (1) to measure the effectiveness and to develop scale of perceived customer orientation, to measure customer satisfaction when Public sector marketing is implemented and (2) to analyze public sector marketing effect for customer orientation in public services based on the proposed conceptual framework (see Fig. 1).

\section{Methods}

In order to measure the effectiveness we have chosen the railway sector especially the fast train services in china. The main reason for choosing the below motioned methodology is that it provides the comprehensive relationship between the service provider and service users, it reflects the opinion of the customer and shows the optimum level of customer orientation in the public sector. The effectiveness of such a sector which provides services can be measured according to the opinion that consumers in the target groups have the (Table 1) characteristics. The effectiveness of such a sector which provides services can be deliberate according to the outlook that clients in the target groups have the subsequent distinctiveness.

$\begin{array}{cl}\text { Characteristics } \\ \checkmark & \text { Speed } \\ \checkmark & \text { Price } \\ \checkmark & \text { Comfort } \\ \checkmark & \text { Reliability } \\ \checkmark & \text { Accessibility } \\ \checkmark & \text { cleanliness and } \\ \checkmark & \text { maintenance of station facilities } \\ \checkmark & \text { Safe/ Security } \\ \checkmark & \text { Schedule span } \\ \checkmark & \text { Understand the needs of the passenger } \\ \checkmark & \text { Ease of buying tickets } \\ \checkmark & \text { provision of information about train schedules and platforms } \\ \checkmark & \text { The quality of facilities and services (e.g. toilets, shops, cafes) in railway stations. } \\ \checkmark & \text { Complaint handling mechanism } \\ \checkmark & \text { Responsiveness } \\ \checkmark & \text { Service quality at station } \\ \checkmark & \text { Assurance } \\ & \end{array}$

\section{Data Collection}

The above attributes isolated into a few parts which are clear to the client (train traveler) and which can be judge independently. Data collected through the questionnaire and the target group can state their opinion against variable (Table1). Questionnaire based on using ordinal scale division from these opinion every characteristic will be assigned an appreciation weight age.

Table 1. Assessment table of fast train service in China

\begin{tabular}{|c|c|c|c|c|c|c|c|}
\hline \multicolumn{8}{|l|}{ Characteristics } \\
\hline & --- & -- & - & $+/-$ & + & ++ & +++ \\
\hline Speed & Very bad & Bad & Moderate & Sufficient & Good & Very good & Excellent \\
\hline Price & II & /I & II & /I & /I & /I & /I \\
\hline Comfort & Very high & High & Fairly high & Reasonable & e low & Very low & Minimal \\
\hline Reliability & Very bad & Bad & Moderate & Sufficient & Good & Very good & Excellent \\
\hline Accessibility & II & II & II & /I & II & II & II \\
\hline cleanliness and maintenance of station facilities & /I & /I & /I & /I & /I & /I & II \\
\hline
\end{tabular}




\begin{tabular}{|c|c|c|c|c|c|c|c|}
\hline Safe/ Security & /I & II & II & /I & /I & II & II \\
\hline Schedule span & II & II & /I & /I & II & II & /I \\
\hline Understand the needs of the passenger & /I & /l & /l & /I & // & /I & /l \\
\hline Ease of buying tickets & /I & /l & /l & /I & /I & II & /l \\
\hline provision of information about train schedules and platforms & /I & /I & II & /l & /I & II & /I \\
\hline $\begin{array}{l}\text { The quality of facilities and services (e.g. toilets, shops, cafes) in } \\
\text { railway stations. }\end{array}$ & II & II & II & II & II & II & /I \\
\hline Complaint handling mechanism & /l & /l & /l & /l & /l & /I & /l \\
\hline Responsiveness & /I & II & /I & /I & II & II & II \\
\hline Service quality at station & /I & /l & /l & /l & /I & /l & /I \\
\hline Assurance & /I & II & II & 11 & /1 & /I & /1 \\
\hline
\end{tabular}

This applies in particular to reach measurement, satisfaction measurement and result measurement. Organization that explicitly pay attention to these types of measurement will also have an internal climate favorable for customer oriented methods.

\section{Results and Discussion}

Table 2. Result Assessment table of fast train service in China

\begin{tabular}{|c|c|c|c|c|c|c|c|}
\hline \multirow[t]{2}{*}{ Characteristics } & \multicolumn{6}{|c|}{ Opinion of the fast train user $(\%)$} & \multirow{2}{*}{$\begin{array}{c}\mathrm{N}=350 \\
+++\end{array}$} \\
\hline & -- & -- & - & $+1-$ & + & ++ & \\
\hline Speed & 0 & 0.9 & 0.6 & 5.1 & 2.6 & 47.1 & 43.7 \\
\hline Price & 0 & 13.4 & 18.0 & 56.0 & 3.7 & 8.0 & 0.9 \\
\hline Comfort & 0 & 0.3 & 1.1 & 11.7 & 11.7 & 59.7 & 15.4 \\
\hline Reliability & 1.7 & 2.6 & 8.6 & 21.1 & 8.0 & 44.6 & 13.4 \\
\hline Accessibility & 1.1 & 6.3 & 28.3 & 11.1 & 8.3 & 32.3 & 12.6 \\
\hline $\begin{array}{l}\text { cleanliness and } \\
\text { maintenance of station facilities }\end{array}$ & 0 & 1.1 & .3 & 10.9 & 12.0 & 50.3 & 25.4 \\
\hline Safe/ Security & 0 & 0.6 & 1.1 & 5.7 & 8.0 & 52.6 & 32.0 \\
\hline Schedule span & 0 & 0.6 & 0.3 & 7.7 & 10.6 & 40.3 & 40.6 \\
\hline Understand the needs of the passenger & 0 & 1.1 & 4.3 & 25.1 & 22.6 & 34.9 & 12.0 \\
\hline Ease of buying tickets & 2.0 & 0.6 & 2.0 & 9.1 & 15.7 & 32.6 & 38.0 \\
\hline provision of information about train schedules and platforms & 0 & 0 & 1.5 & 7.1 & 8.3 & 49.1 & 34.0 \\
\hline The quality of facilities and services (e.g. toilets, shops, cafes) in railway stations. & 0 & 0.3 & 3.1 & 17.1 & 10.9 & 44.6 & 24.0 \\
\hline Complaint handling mechanism & 2.0 & 3.7 & 5.1 & 19.7 & 16.6 & 37.7 & 15.1 \\
\hline Responsiveness & 4.3 & 16.0 & 21.1 & 31.7 & 8.0 & 16.0 & 2.9 \\
\hline Service quality at station & 0 & 5.1 & 5.7 & 36.3 & 16.3 & 31.1 & 5.4 \\
\hline Assurance & 1.4 & 2.9 & 2.6 & 40.0 & 12.3 & 32.0 & 8.9 \\
\hline
\end{tabular}

Meeting with the real score yields the picture reflected in table 3. We may finish up from this table the price of the Fast train services merits consideration. The client is fully satisfied by the other trademark utilized as a part of this study also: more than the standard rates of clients demonstrate that they are satisfied by these attributes.

Table 3. Customary for assorted characteristic as per their actual values

\begin{tabular}{|c|c|c|c|}
\hline \multirow{3}{*}{$\begin{array}{l}\text { Characteristic } \\
\text { Speed }\end{array}$} & Assumed Standard (\%) & \multicolumn{2}{|c|}{ Reality (\%) Deviation (\%) } \\
\hline & Sufficient ,Reasonable or higher & & \\
\hline & 80 & 98 & +18 \\
\hline Price & 80 & 69 & -11 \\
\hline Comfort & 80 & 98 & +18 \\
\hline Reliability & 80 & 87 & +7 \\
\hline Accessibility & 80 & 64 & -16 \\
\hline cleanliness and maintenance of station facilities & 80 & 99 & +19 \\
\hline Safe/ Security & 80 & 98 & +18 \\
\hline Schedule span & 80 & 99 & +19 \\
\hline Understand the needs of the passenger & 80 & 95 & +15 \\
\hline Ease of buying tickets & 80 & 95 & +15 \\
\hline provision of information about train schedules and platforms & 80 & 98 & +18 \\
\hline The quality of facilities and services (e.g. toilets, shops, cafes) in railway stations. & 80 & 96 & +16 \\
\hline
\end{tabular}


Complaint handling mechanism

Responsiveness

Service quality at station

Assurance

\begin{tabular}{llc|}
80 & 89 & +9 \\
80 & 59 & -21 \\
80 & 89 & +9 \\
80 & 93 & +13
\end{tabular}

Intentionally utilizing one or a few of the sorts of adequacy estimation examined above naturally upholds sound recognizable proof of the target groups. This applies specifically to achieve estimation, fulfillment estimation and result estimation. Public sector organization in China expressly pay consideration on these sorts of estimation will likewise have an inner atmosphere ideal for customer oriented methods.

\section{Summary and Conclusion}

In this study, we developed the conceptual framework from the brief literature review; Fig 1 explained the focus of public sector marketing towards public services in order to meet the customer satisfaction. The conceptual framework suggested the overall process and creates a positive prelateship between customer orientation and customer satisfaction. This relationship further explained through measuring effectiveness. The result of the survey used in this study showed the fast train user satisfaction toward services, we used different parameter to measure the effectiveness, in table 3 indicate that the price followed by accessibility and responsiveness as signals of customer satisfaction and tolerable pleasing of customer wants. The remaining attributes of the fast train services in china, which shows that high level of satisfaction from the customer (user). This study here affirms that the wide standards of the marketing and customer orientation idea are pertinent in public segment, examines and presents illustrations of possible strategies, prerequisites and methods for the viability estimation that might be used as a piece of public sector. In the previous studies Zaheer (2015) mentioned that in China, Public sector has enthusiastically brought significant improvement for fulfillment of the need citizen and also for establishment of innovative offerings for public interests and Chinese public sector posses a huge prospective to support the government in on condition that effectual services for the public at large.

At the outline stage for client introduction forms at public sector, it is important to recognize the customer, which may be aggregate (e.g., associations and other government offices) or individual (client or native). Subsequent to distinguishing customers who are beneficiaries of the services, and consequently the members and beneficiaries of the procedure of its execution, it is important to decide their need. Before the difficulties and opportunities brought by globalization, and in addition of the quick advancement of innovation, demographic changes, rising desires of citizens and rivalry from the private sector, the Chinese Government ought to figure out how to proceed with the investigation and abuse of better approaches to enhance the circumstance of public administration in the country. In closing we may reason that customer orientation in public sector organizations is an especially obliging and vital thought.

\section{References}

Appiah-Adu, K., \& Singh, S. (1998). Customer orientation and performance: a study of SMEs. Management Decision, 36(6), 385-394.

Bean, J., \& Hussey, L. (2012). Marketing Public Sector Services: essential skills for the public sector. HB publications.

Bolton, M. (2003). Public sector performance measurement: Delivering greater accountability. Work Study, 52(1), 20-24.

Burton, S. (1999). Marketing for public organizations: new ways, new methods. Public Management an International Journal of Research and Theory, 1(3), 373-385.

Chapman, D., \& Cowdell, T. (1998). New public sector marketing. Financial Times Pitman Pub.

Chiang, M. C. (1999). Government reconstruction and customer-oriented service mindset. National Central Library Taiwan Branch Library Journal, 6(1), 1-17.

Church, D. (n.d.). Government Sector Fairs Poorly in Adoption of Marketing Best Practices.

Claver, E., Llopis, J., Gascó, J. L., Molina, H., \& Conca, F. J. (1999). Public administration: From bureaucratic culture to citizen-oriented culture. International Journal of Public Sector Management, 12(5), 455-464.

Cousins, L. (1990). Marketing Planning in the Public and Non-profit Sectors. European Journal of Marketing. http://doi.org/10.1108/030 90569010006759 .

Cowell, D. W., \& Advertising, C. (1984). The marketing of services. Heinemann London.

Deshpandé, R., Farley, J. U., \& Webster Jr, F. E. (1993). Corporate culture, customer orientation, and innovativeness in Japanese firms: a quadrad analysis. The Journal of Marketing, 23-37.

Fang, Xiaoping, Chen, Zhiya \& Li, Zhizhong. (2003). A discussion on the Feasibility of Regular Rail Transport Carrying Container between Zhujiang Delta and Yantian Port. System Engineering, 21(2): 74-78

Font, J. (1997). Quality measurement in Spanish municipalities: transferring private sector experiences. Public Productivity \& Management Review, 44-55.

Gianakis, G. A. (2002). The promise of public sector performance measurement: anodyne or placebo? Public Administration Quarterly, 
$35-64$.

Kohli, A., \& Jaworski, B. (1990). Market orientation: the construct, research propositions, and managerial implications. The Journal of Marketing, 54(2), 1-18. http://doi.org/10.2307/1251866.

Kondylis, E. C. (2011). Considerations on the public sector organizations performance: a systems approach. Journal of Applied Business Research (JABR), 5(4), 15-19.

Kotler, P., \& Lee, N. R. (2007). Marketing in the Public Sector: The Final Frontier. Public Manager, 36, 12-17.

Kotler, P., \& Zaltman, G. (1971). Social marketing: an approach to planned social change. Journal of Marketing, 35(3), 3-12. http://doi.org/Retrieved from EBSCO HOST.

Madill, J. J. (1998). Marketing in government. The Journal of Public Sector Management, 28(4), 9-18.

Marini, F. (1993). "Can't Get No Satisfaction": Customers, Citizens, Service, and Satisfaction. JSTOR.

Mellors, J. (1993). The commercialisation of common services provided by the Department of Administrative Services: outcomes and emerging issues. Australian Journal of Public Administration, 52(3), 329-338.

Mintz, J. J. H., Partner, M., \& Sector, P. (2006). Optimum Online is the Web site edition of Optimum : The Journal of Public Sector The Case for Marketing in the Public Sector Introduction:, 36(4), 1-18.

Narver, J. C., \& Slater, S. F. (1990). The effect of a market orientation on business profitability. The Journal of Marketing, 20-35.

Parker, R., \& Bradley, L. (2000). Organisational culture in the public sector: evidence from six organisations. International Journal of Public Sector Management, 13(2), 125-141.

Proctor, T. (2007). Public Sector Marketing. Health Promotion.

Reid, M. (2008). Contemporary marketing in professional services. Journal of Services Marketing, 22(5), 374-384.

Sargeant, A. (1999). Marketing management for nonprofit organizations. Lnb.It. Retrieved from http://www.Inb.lt/stotisFiles/uploaded Attachments/15_Marketing_management2010125104422.pdfinpapers2://publication/uuid/OAC73C6D-1A50-4B4A-8AED389EDFC60267Inpapers2://publication/uuid/7F75E00B-6AA0-4BD0-98E9-DCA590232023.

Serrat, O. (2010). Marketing in the Public Sector. Washington, DC: Asian Development Bank.

Shapiro, B. P. (1988). What the hell is market oriented? HBR Reprints.

Zaheer, A., Wei, S., Chong, R., Abdullah, M., \& Khan, K. (2015). High Aiming in Public Sector Marketing: A Way Forward to Boost China's Economy. Mediterranean Journal Of Social Sciences, 6(6), 107.Retrieved from http://www.mcser.org/journal/index.php/ mjss/article/view/7919

Zaheer, A. N., Wei, S., Xuehe, Z., Khan, K. U., \& Anjum, M. N. (2015). Analyzing Public sector marketing in: Acase study from Anhui province. Advances in Social Sciences Research Journal, 2(6), 27-35. http://doi.org/http://dx.doi.org/10.14738/assri.26.1210 